\title{
MANAJEMEN HUMAS SMK MUHAMMADIYAH 9 WAGIR UNTUK MENINGKATKAN KREDIBILITAS SEKOLAH
}

\author{
Agung Deddiliawan Ismail $1^{\star \star}$, Anis Farida Jamil ${ }^{2}$, Adityo $^{3}$ \\ ${ }^{1 *}$ Program Studi Pendidikan Matematika, Universitas Muhammadiyah Malang \\ ${ }^{2}$ Program Studi Pendidikan Matematika, Universitas Muhammadiyah Malang \\ ${ }^{3}$ Program Studi Pendidikan Bahasa Inggris, Universitas Muhammadiyah Malang \\ ${ }^{*}$ Corresponding author : \\ E-mail:deddiliawan@gmail.com
}

\section{Diterima 2 November 2018, Disetujui 7 November 2018}

\begin{abstract}
ABSTRAK
Salah satu cara meningkatkan kredibilitas sekolah adalah dengan memperkenalkan sekolah kepada masyarakat luas. Dalam hal ini, publikasi sekolah menjadi sangat penting. Tujuan dari kegiatan pengabdian ini adalah memberikan pendampingan kepada humas SMK Muhammadiyah 9 Wagir untuk meningkatkan kredibilitas sekolah dengan cara membuat website sekolah agar sekolah dapat dikenal masyarakat luas. Metode yang digunakan untuk melaksanakan kegiatan pendampingan ini antara lain 1) mengadakan workshop manajemen humas, 2) mengadakan workshop pengenalan website, 3) melakukan pendampingan pembuatan website, dan 4) melakukan evaluasi. Hasil yang diharapkan pada kegiatan ini adalah website SMK Muhammadiyah 9 Wagir yang siap diakses oleh masyarakat luas dan artikel ilmiah yang akan dipublikasikan di jurnal nasional atau internasional.
\end{abstract}

Kata Kunci: Manajemen Humas, Kredibilitas Sekolah, Website SMK Muhammadiyah 9 Wagir

\section{ABSTRACT}

In increasing school credibility, introducing the school to a wider community is critical. In the case being analyzed in this research, school publications are considered critically important as the solution of the problems. The purpose of this community service is to provide assistance to public relations of the Muhammadiyah Vocational School 9 Wagir to increase school credibility by creating a school website so that the school can be known to the wider community. The methods used to carry out this mentoring activity included 1) designing a public relations management workshop, 2) conducting a website introduction workshop, 3) conducting website assistance, and 4) conducting evaluations. The expected results of this activity are the Muhammadiyah Vocational School 9 Wagir website that is ready to be accessed by the wider public and scientific journal articles.

Keywords: Public Relations Management, School Credibility, Website of SMK Muhammadiyah 9 Wagir.

\section{PENDAHULUAN}

ASEAN Free Trade Area (AFTA) merupakan wujud kesepakatan dari negaranegara ASEAN untuk meningkatkan persaingan global diberbagai bidang. Bagi negara berkembang seperti Indonesia, adanya persaingan global menuntut untuk meningkatkan segala sektor negara, baik politik, ekonomi, pendidikan, maupun ilmu pengetahuan dan teknologi. Peningkatan semua sektor tentunya dilaksanakan melalui pembangunan bangsa. Pengembangan Sumber Daya Manusia (SDM) adalah hal yang paling penting untuk pembangunan suatu bangsa. Sekolah Menengah Kejuruan (SMK) adalah bagian terpadu dari Sistem Pendidikan Nasional, yang mempunyai peranan penting didalam menyiapkan dan pengembangan SDM. Tetapi hal ini berbanding terbalik dengan kondisi dan fasilitas yang terdapat pada beberapa SMK. Beberapa SMK yang terdapat di Malang, khususnya di wilayah kabupaten, ternyata masih banyak ditemukan SMK yang perlu mendapat perhatian lebih agar proses pembelajaran dapat dilakukan dengan 
maksimal sehingga lulusan yang dihasilkan benar - benar terampil.

SMK Muhammadiyah 9 Wagir merupakan salah satu SMK binaan Universitas Muhammadiyah Malang yang perlu mendapat perhatian. SMK yang terletak di Desa Pandanrejo ini berjarak $18 \mathrm{~km}$ dari kampus UMM. Untuk mencapai lokasi sekolah harus melewati jalan kecil yang berjarak sekitar 200 meter dari jalan Raya Pandansari. Pada awal berdirinya pada tahun 2007 bangunan SMK Muhammadiyah 9 Wagir merupakan bangunan wakaf dan berbagi dengan sekolah Taman Kanak-Kanak (TK). Sampai sekarang gedung SMK ini memiliki gedung yang kurang layak yaitu terdiri dari dua ruangan kelas, 1 ruang peralatan, 1 ruang laboratorium komputer, dan 1 ruangan kantor. SMK Muhammadiyah 9 Wagir tidak memiliki ruang guru dan ruang kepala sekolah. Semua pegawai baik kepala sekolah, guru dan staf administrasi ditempatkan dalam satu ruangan di ruangan kantor.

Secara keseluruhan pegawai di SMK Muhammadiyah 9 Wagir berjumlah 18 orang yang terdiri dari 1 kepala sekolah, 16 guru mata pelajaran, dan 1 staf tata usaha. Jumlah siswa secara keseluruhan sebanyak 41 orang, dengan rincian siswa kelas $X$ berjumlah 22 orang, siswa kelas XI berjumlah 5 orang, dan siswa kelas XII berjumlah 14 orang. SMK Muhammadiyah 9 Wagir hanya membuka satu bidang keahlian yaitu Teknik Komputer dan Informatika dengan kompetensi Teknik Komputer dan Jaringan. Sebagai penunjang dalam kegiatan pembelajaran sekolah memiliki satu ruang sebagai laboratorium komputer.

Salah satu hal penting untuk diperhatikan suatu lembaga pendidikan adalah kredibilitas. Meskipun SMK Muhammadiyah 9 Wagir hanya membuka satu bidang keahlian yaitu Teknik Komputer dan Informatika, SMK ini berusaha untuk menjadi sekolah yang dapat dipercaya oleh masyarakat luas. Hal ini tampak dari usaha sekolah yaitu dengan menambah gedung baru untuk menjamin terlaksananya proses pendidikan yang baik sehingga mampu menghasilkan lulusan-lulusan yang berprestasi. Hal lain yang dapat meningkatkan tingkat kepercayaan masyarakat terhadap sekolah adalah manajemen sekolah. Manajeman humas merupakan salah satu manajeman sekolah yang perlu diperhatikan karena lingkup kinerja humas berhubungan dengan pihak luar sekolah. Pandangan pihak luar sekolah terhadap suatu sekolah tergantung manajemen humas yang terdapat pada sekolah tersebut. Kinerja humas dikatakan baik jika pandangan pihak luar sekolah terhadap suatu sekolah positif. Sehingga hal ini dapat meningkatkan kredibilitas sekolah dikalangan masyarakat.

Publikasi sekolah merupakan salah satu tugas humas. Publikasi merupakan hal penting karena dengan publikasi suatu sekolah dapat dikenal masyarakat luas. Publikasi dapat dilakukan melalui berbagai cara. Zaman sekarang diera tekonologi semakin maju website merupakan cara praktis sebagai media publikasi. SMK Muhammadiyah 9 Wagir merupakan sekolah dengan letak yang kurang strategis yaitu untuk mencapai lokasi sekolah harus melewati jalan kecil yang berjarak sekitar 200 meter dari jalan Raya Pandansari. Lokasi yang kurang strategis inilah yang menyebabkan SMK Muhammadiyah 9 Wagir kurang banyak dikenal masyarakat luas. Pengadaan website sekolah SMK Muhammadiyah 9 Wagir merupakan salah satu cara praktis untuk mempublikasi sekolah sehingga sekolah tersebut dapat dikenal oleh masyarakat luas.

Berdasarkan hasil analisis di atas permasalahan mitra SMK Muhammadiyah 9 Wagir antara lain.

a. Kurangnya motivasi tenaga struktural, tenaga fungsional, maupun tenaga teknis untuk memajukan dan meningkatkan publikasi sekolah.

b. Belum ada manajemen humas yang baik.

Berdasarkan pemaparan permasalahan di atas, Lembaga Univeritas Muhammadiyah Malang memiliki kewajiban untuk membantu meningkatkan kredibilitas sekolah. Dalam hal ini dirancang pengabdian yang bertujuan untuk memberikan motivasi guru dan mendampingi dalam penataan manajemen humas di SMK Muhammadiyah 9 Wagir. Dengan diadakan "Pendampingan Manajemen Humas di SMK Muhammadiyah 9 Wagir" dirapkan dapat mengatasi kendala yang ada.

Pelaksanaan pendampingan untuk manajemen humas agar meningkatkan kredibilitas sekolah adalah salah satunya melalui publikasi yang baik oleh sekolah. Publikasi dapat didukung melalui website sekolah yang belum dimiliki SMK Muhammadiyah 9 Wagir. Pendampingan ini dilakukan dengan memberikan pelatihan sampai dengan pembuatan website sekolah. Secara rinci luaran 
yang dihasilkan dalam pelaksanaan kegiatan ini adalah sebagai berikut.

Salah satu luaran yang dihasilkan dalam pelaksanaan kegiatan ini yaitu website SMK Muhammadiyah 9 Wagir. Hal yang dilakukan untuk menghasilkan website tersebut adalah 1) melaksanakan workshop bagi manajemen humas untuk mendapatkan informasi mengenai manajemen humas yang baik, 2) melaksanakan workshop pengenalan desain web, 3) pendampingan pembuatan desain web.

Luaran yang lain adalah artikel yang dipublikasikan baik d jurnal atau prosiding. Artikel yang dipublikasikan merupakan artikel hasil kegiatan pendampingan manajemen humas untuk meningkatkan kredibilitas sekolah.

\section{METODE PELAKSANAAN}

Metode pelaksanaan kegiatan pengabdian masyarakat internal ini diawali dengan mengadakan observasi awal dan wawancara kepada guru-guru di SMK Muhammadiyah 9 Wagir. Observasi ini bertujuan untuk mengetahui kondisi sekolah secara langsung dan mendapatkan informasi mengenai data sekolah maupun permasalahanpermasalahan yang dihadapi. Kegiatan pengabdian ini merupakan lanjutan kegiatan pengebdian sebelumnya dimana permasalahan yang lain yang dimiliki sekolah adalah minimnya publikasi sekolah sehingga kredibilitas sekolah menjadi buruk. Solusi yang ditawarkan untuk mengatasi permasalahan tersebut pada kegiatan pengabdian masyarakat internal ini sebagai berikut.

\section{Workshop Manajemen Humas}

Hubungan Masyarakat (Humas) sangat penting dalam manajemen pendidikan dikarenakan humas mempunyai fungsi pokok dalam manajemen pendidikan yaitu dapat menarik perhatian masyrakat umum sehingga meningkatkan relasi serta animo masyarakat terhadap lembaga pendidikan tertentu (Gunawan, 2002). Kegiatan pertama yang dilakukan adalah melaksanakan workshop untuk manajemen humas. Workshop ini bertujuan untuk memberikan informasi kepada manajemen humas SMK Muhammadiyah 9 Wagir tentang kinerja manajemen humas yang baik. Pemateri kegiatan workshop manajemen humas ini adalah guru SMK Muhammadiyah 7 Gondanglegi yang menjabat sebagai humas sekolah. Sebagaimana diketahui bahwa SMK Muhammadiyah 7 Gondanglegi adalah salah satu SMK unggulan yang telah meraih banyak prestasi. SMK
Muhammadiyah 7 Gondanglegi merupakan sekolah yang telah memiliki semua manajemen yang baik, baik manajemen mutu, manajemen ketenagaan maupun manajemen humas. Diharapkan pemateri dari SMK Muhammadiyah 7 Gondanglegi dapat memberikan ilmunya untuk memperbaiki kinerja manajemen humas di SMK Muhammadiyah 9 Wagir. Selain itu, diharapkan motivasi dari humas sekolah dapat bertambah untuk memajukan sekolah.

\section{Workshop Pembuatan Website}

Salah satu cara meningkatkan kredibilitas sekolah adalah menyiapkan publikasi sekolah dengan baik. Publikasi sekolah adalah program humas untuk memenuhi tugasnya dalam meningkatkan animo masyarakat. Sekolah diharapkan dapat dikenal oleh masyarakat luas sehingga kepercayaan masyarakat dapat bertambah. Pada zaman teknologi saat ini, publikasi dilakukan melalui website. Sehingga kegiatan selanjutnya yang akan dilakukan adalah workshop pembuatan website bagi humas SMK Muhammadiyah 9 Wagir. Pemateri pada kegiatan ini adalah Bapak Agung Deddiliawan Ismail dan Ibu Anis Farida Jamil selaku ketua dan anggota kegiatan pengabdian ini. Bapak Agung dan Ibu Anis adalah dosen pengampu matakuliah desain web sehingga pemateri adalah pakar pada bidangnya. Untuk menunjang hasil website agar dapat dibaca masyarakat luas tidak hanya nasional namun juga internasional, maka kepakaran dalam bidang Bahasa Inggris dibutuhkan yakni kepakaran dari Bapak Adityo, M.A yang juga salah satu anggota tim. Hasil yang diharapkan untuk kegiatan workshop pengenalan website ini adalah humas sekolah dapat mengetahui cara pembuatan website.

\section{HASIL DAN PEMBAHASAN}

\section{Workshop Manajemen Humas}

Pelatiah Humas dilaksanakan pada tanggal 31 Agustus 2018. Pada kegiatan pelatihan terdapat beberapa materi yang disampaikan diantaranya adalah Ilmu Komunikasi, Fungsi Humas, Prinsip Dasar Humas, Proses Public Relations/Kehumasan, Pengantar Managemen Kehumasan, Perencanaan Program Kehumasan, Media yang digunakan dalam kegiatan kehumasan, sponsorship, managemen hubungan media, monitoring dan evaluasi program kehumasan, Peran teknologi informasi dalam managemen kehumasan, managemen strategi.

Setelah memberikan materi staf humas sekolah diminta untuk mengidentifikasi 
visi, misi dan tujuan, fasilitas, managemen, staf, prestasi SMK Muhammadiyah 9 Wagir. Setelah mengumpuldan data tersebut, staf humas diminta untuk mempresentasikan dihadapan tim pengabdian dan staf guru sebagai media untuk belajar berkomunikasi dalam mempromosikan sekolah. Diakhir presentasi tim pengabdian memberikan masukan pada masing-masing presenter menangani hal hal yang dianggap kurang seperti, cara berkomunikasi yang positif dan persuasif, staf humas harus lebih percaya diri dalam menyampaikan informasi. Informasi yang disampaikan harus terstruktur dan sistematis.

\section{Workshop Pembuatan Website}

Kegiatan workshop di SMK Muhammadiyah 9 Wagir dilaksanakan pada hari Jumat tanggal 31 Agustus 2018. Ruang yang digunakan untuk workshop adalah di kantor guru dikarenakan hanya ada 3 ruang kelas dan semuanya digunakan pembelajaran. Pemateri pada kegiatan ini adalah Bapak Agung Deddiliawan Ismail dan Ibu Anis Farida Jamil. Keterlibatan mahasiswa pada kegiatan ini adalah sebagai pemateri pendamping atas nama Filza Helmi Gunawan dan Meinito Sindi. Bapak Agung dan Ibu Anis adalah dosen pengampu matakuliah desain web sehingga pemateri adalah pakar pada bidangnya. Untuk menunjang hasil website agar dapat dibaca masyarakat luas tidak hanya nasional namun juga internasional, maka kepakaran dalam bidang Bahasa Inggris dibutuhkan yakni kepakaran dari Bapak Adityo, M.A yang juga salah satu anggota tim. Hasil kegiatan workshop pengenalan website ini adalah humas sekolah mengetahui cara pembuatan website sekolah dengan menggunakan domain sch.id.

\section{Pendampingan Pembuatan Website}

Setelah dilakukan pemberian materi dan workshop pelatihan bagaimana cara membangun dan melakukan managemen pada website sekolah. Tim Pengabdian melakukan pendampingan secara berkala yaitu satu minggu sekali selama 2 minggu. Pendampingan dan memantauan website dilakukan secara online dengan mengamati website sekolah. Untuk komunikasi antara tim pengabdian dan pihak sekolah dilakukan dengan menggunkan email dan jejaring social. Pendampingan pertama dilakukan pada hari Sabtu tanggal 8 September 2018. Diskusi yang dilakukan adalah berkaitan dengan konten atau isi website. Konten yang akan diisi adalah "header" lambing sekolah SMK Muhammadiyah 9 wagir sebagai identitas sekolah, konen lain adalah informasi profil sekolah yang terdiri dari visi dan misi, tujuan dan sejarah SMK muhammadiyah 9 Wagir. Konten selanjutnya yang akan di masukkan adalah galeri foto yang berisi kegiatan-kegiatan yang telah dilaksanakan oleh sekolah. Konten lain adalah kontak sekolah dimana berisi mengenai alamat, kota, propinsi, kode post, telp, email dan alamat website.

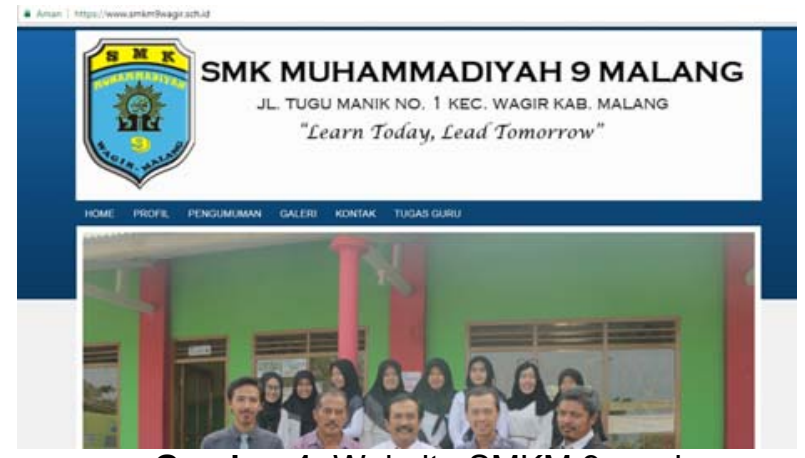

Gambar 1. Website SMKM 9 wagir

Pendampingan kedua dilaksanakan pada hari Sabtu tanggal 14 September 2018. Tim pengambian memantau perkembangan updating konten yang telah didiskusikan pada halaman website. Diskusi yang dilakukan pada pendampingan kedua ini adalah berkaitan dengan tata letak bagianbagian website yang perlu dioptimalkan. Selain itu tim pengabdian menginformasikan pada petugas/guru yang bertugas untuk memeliharaa website agar selalu mengudate informasi-informasi terbaru agar website terbaca oleh google dan dapat dibaca oleh pihak lain. Pada kegiatan ini, guru yang bertugas memelihara website sekolah, kami beri buku panduan pemeliharaan website sekolah sehingga keberlanjutan website sekolah dapat terlaksana.

\section{Evaluasi}

Kegiatan evaluasi dilakukan setelah semua kegiatan workshop dan pendampingan pembuatan website selesai. Evaluasi dari kegiatan ini adalah meningkatnya kredibilitas sekolah dengan adanya website resmi sekolah dengan alamat https://www.smkm9wagir.sch.id/. Berikut tampilan website sekolah. 


\section{SIMPULAN DAN SARAN}

\section{Kesimpulan}

Kegiatan pengabdian ini dilaksanakan dengan diawali oleh workshop manajemen humas. Kegiatan inti dilaksanakan setelahnya yaitu pelatihan pembuatan website sekolah dilanjut dengan pendampingan pembuatan dan pengelolaan website sekolah. Kegiatan terakhir adalah evaluasi. Kegiatan pengabdian ini memiliki luaran yaitu website resmi sekolah yang beralamat https://www.smkm9wagir.sch.id/. Selain itu, tim pengabdi juga memberikan buku petunjuk untuk pengelolaan website sekolah. Luaran lainnya adalah artikel hasil kegiatan pengabdian yang dipublikasikan di jurnal.

\section{Saran}

Untuk pengembangan web sekolah lebih baik jika website sekolah dapat ditautkan dengan website dinas pendidikan kabupaten malang.

\section{DAFTAR RUJUKAN}

Abu-Dhou, I. (2003). School-Based Management (Manajemen Berbasis Sekolah). Buku Serial Dasar-Dasar Perencanaan Pendidikan UNESCO. Terjemahan oleh Aini, Sapto, dan Jauhari. Pengantar oleh Prof. Dr. H. A. Malik, M.Sc. Jakarta: Logos Wacana IImu.

Engkoswara. (1987). Dasar-Dasar Administrasi Pendidikan. Jakarta: Depdikbud.

Gunawan, Ary H. 2002. Administrasi Sekolah, Administrasi Pendidikan Mikro. Jakarta: Rineka Cipta.

Made, P. (1988). Manajemen Pendidikan. Jakarta: PT. Bina Aksara.

Mondy \& Noe. (1991). Human Resource Management. Massachussets: Allyn \& Bacon. 